\section{BOOK REVIIEW}

\section{ILLUSTRATIONS OF SURGICAL TREATMENT: INSTRUMENTS AND APPLIANCES}

By Eric L. Farquharson. 2nd Edition. E. \& S. Livingstone, Edinburgh. 1942. Price $25 \mathrm{~s}$.

This is an excellently produced and illustrated book. It lives up to the high standards which one has learnt to expect from Messrs. Livingstone and no praise is too high for the manner in which the text and illustrations are set out. The title of the book is misleading. The main part of it deals with the treatment of fractures and injuries and an appendix covering over roo pages describes and illustrates a variety of surgical instruments and appliances. This appendix seems to be totally irrelevant to the first part of the book and could well have been published separately. The author contends that it meets the needs of medical students and postgraduates in describing and naming the commoner surgical instruments but it is hard to see why for this reason it should be included in the same covers as a practical manual on the treatment of fractures. It is also at variance with the excellent quality of the first part of the book that illustrations should be included of such out of date and discredited instruments as the intra-medullary bone peg. It must be mentioned in fairness to the author that he forsees this objection to the book and in his preface defends the inclusion of the section on instruments and appliances.

A preliminary section deals with infusion and transfusion. The technique of these operations is described in detail and should prove a most helpful guide to those undertaking such operations for the first time and also to many who are already familiar with the procedures. The rest of the book up to the appendix deals largely with the treatment of fractures of the limbs and trunk, with short sections on the treatment of the commoner orthopaedic conditions such as tuberculosis of the hip joint and congenital deformities of the foot. Discussion of the principles of treatment and all other abstractions is avoided so that the book is essentially a practical manual and describes and illustrates modern methods of fracture treatment. The author is to be congratulated in having produced such a clear and practical account of his subject and the book is full of technical points which can be assimilated with profit by the experienced surgeon as well as by the post-graduate student.

It is essential in the treatment of fractures that the surgeon should have some natural mechanical aptitude and should develop it to the full. It is not enough to have a sound appreciation of principle and the indications for different methods of treatment; it is also necessary to carry out the mechanical principles involved in a workmanlike and efficient manner. The young surgeon seeking for guidance in such matters will be amply rewarded by reading and re-reading this book. It will not serve him in very good stead for examination purposes but it will help to fit him for the much more important task of treating his patients.

\section{SPECIAL NUMBERS OF THE JOURNAL}

Special numbers have been published from time to time, each dealing comprehensively with a particular branch of medicine or surgery. These special numbers are as follows, and copies, price 2s. each, post free, may be obtained from the Fellowship of Medicine, I Wimpole Street, London, W.I. A list of contents of any individual number will be sent on application.

OBSTETRICS

(August, 1933)

OPHTHALMOLOGY

(August, 1934)

NEUROLOGY

(April, 1935)

UROLOGY

(November, 1935)

Cardiology

(April, r936)

Proctology

(August, I936)

NEPHRITIS

(February, 1937)

RheumatisM

(September, 1937)

ORTHOPEDICS

(October, 1937)

Tropical Diseases

(November, 1938)

Cerebral Tumours

(May, 1939)

Focal SePsis

(February, 1940)

*War Wounds of the Chest

(March, 1940)

*War Wounds of the Abdomen (April, 1940)

*IVAR Wounds of the Limbs

(May, 1940)

*War Wounds of the Eye and Orbit (June, I940)

*War Wounds of the Head and Face (July, 1940)

Carcinoma of the Lung

(February, 1943)

* "War Wounds and Injuries," published by Edward Arnold \& Co., London, is a reproduction of these five special numbers in book form. A second edition, revised and enlarged, is now available, price 35/-. 